\title{
Werden Sie agil!
}

\section{Liebe Leserinnen und Leser,}

die Digitalisierung der Wirtschaft wird von einer Reihe neuer Schlagworte begleitet: Industrie 4.0, Big Data, künstliche Intelligenz, Internet der Dinge und viele andere mehr. Ein weiteres fällt häufig, wenn es darum geht, wie das Management die Digitalisierung bewältigen soll: Agilität.

Der Begriff ist nicht neu. Er kam vor etwa 20 Jahren im Zuge der Entwicklung der Logistik zum Supply Chain Management auf. Dieses will Wertschöpfungsketten ganzheitlich steuern, über viele Akteure hinweg, die nicht unter dem Dach einer gemeinsamen Hierarchie stehen, sondern unabhängig sind. Die Umsetzung dieser Idee bedarf einer leistungsfähigen IT, aber insbesondere auch einer geeigneten Koordinationsform.

Auch bei der heutigen Verwendung des Begriffs Agilität steht Koordination im Fokus: Der Kontext ist nun die hohe Unsicherheit - kein Feld, in dem sich größere Unternehmen gerne bewegen. Diese sind auf Effizienz getrimmt und lieben Sicherheit. Hier können sie sich optimieren und dafür komplexe Regelsysteme aufbauen. Unsicherheit lässt solche festen Strukturen nicht zu. Führen unter Unsicherheit heißt, schnell auf neue Umstände reagieren zu können. Dies geht nur beziehungsweise am besten dann, wenn das Know-how aller Beteiligten genutzt wird, wenn eine Form gefunden wird, die eine hohe Interaktion zwischen den Beteiligten ermöglicht.

Paradebeispiel für einen solchen Schwenk ist die Abkehr vom sogenannten „Wasserfallmodell“ in der Software-Erstellung. In diesem stand traditionell ein Lasten- und Pflichtenheft am Beginn des Prozesses, in dem die Anforderungen der Nutzer in Programmmerkmale umgesetzt wurden. Darauf basierend wurde die Software programmiert und dann von den Nutzern abgenommen. Dieser Prozess dauerte lange. Während dieser Zeit erfolgende Veränderungen konnten nicht berücksichtigt werden. War die Software fertig, passte sie häufig nicht mehr. Heute geht man deshalb prototypisch vor, stimmt erreichte Fortschritte ständig mit den Nutzern ab. Der Prozess ist viel stärker teamorientiert und baut das Wissen aller Beteiligten ein, geleitet von der Bereitschaft, ständig zu lernen. Die Entwicklung der Anforderungen und die Entwicklung der Lösungen erfolgen im ständigen Wechselspiel.

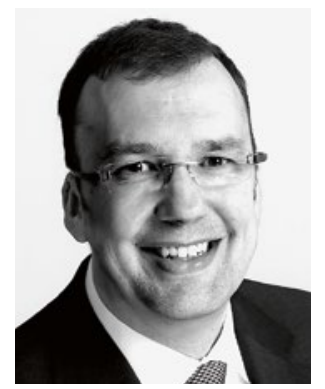

Utz Schäffer

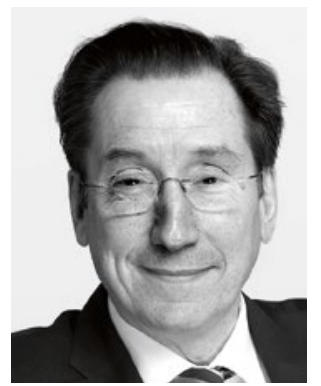

Jürgen Weber
Gibt es vergleichbare Probleme im Aufgabenfeld der Controller? Ja, und zwar ganz offensichtlich dann, wenn es um den Aufbau neuer Informations- und Steuerungssysteme geht. Hier können Controller selbst ausprobieren, wie Agilität funktioniert, können einen Überblick darüber gewinnen, wo ein agiles Vorgehen dem alten, eher bürokratisch geprägten Weg überlegen ist, können ein Konzept entwickeln, wie agile Steuerung im Kontext einer weiterhin eher bürokratischen Gesamtsteuerung funktionieren kann. Es geht nicht um ein „Entweder-oder“, sondern um ein „Sowohl-als-auch“.

Die Steuerungsaufgabe wird also komplexer. Controller müssen das verstehen und berücksichtigen. Die Umwelt wird ihnen nicht den Gefallen tun, sicherer zu werden. Controller schaffen die neuen Anforderungen am besten dann, wenn sie damit selbst im eigenen Bereich Erfahrung sammeln. Gelegenheiten dazu gibt es genug!

Viel Spaß bei der Lektüre wünschen Ihnen
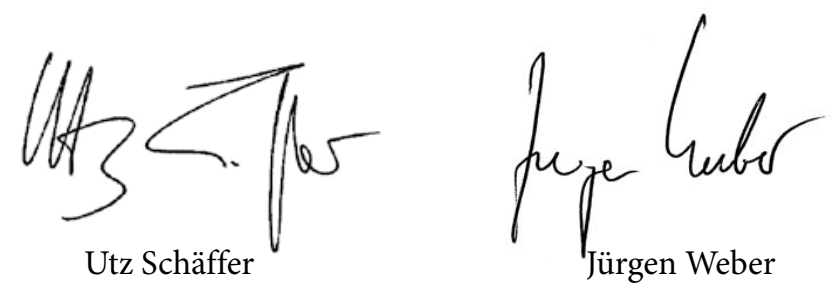